\title{
Microtia and short stature: a new syndrome
}

\author{
Brian Cohen, I Karen Temple, John C Symons, Christine M Hall, Donald G Shaw, \\ Manjit Bhamra, Andrew M Jackson, Marcus E Pembrey
}

\begin{abstract}
Bilateral microtia, absent patellae, short stature, poor weight gain, and characteristic facial features are described in two female sibs. Other skeletal anomalies included complete habitual dislocation of the elbow, slender ribs and long bones, abnormal modelling of the glenoid fossae with hooked clavicles, and clinodactyly. Bone age was significantly delayed and there was flattening of the epiphyses. This unusual combination of features has many similarities to the syndrome described by Hurst et al.
\end{abstract}

In 1988 Hurst et $a l^{1}$ described two unrelated males with small ears, short stature, absent patellae, characteristic facial features, and skeletal anomalies. The boys were matched through the London Dysmorphology Database 'unknowns' group. Both boys had in addition unusual and similar radiographic findings. In particular, there were flat, abnormally modelled glenoid fossae with dislocation of the radial heads and hooked clavicles. Bone age was markedly delayed with abnormal epiphyses in both children. The two boys differed in that the second boy died at 4 days of age and was found to have an atrial septal defect, small adrenal glands, and bilateral hydronephrosis, while the other remained well aged $4 \frac{1}{2}$ years but was found to have an IQ of 60 and craniosynostosis.

Department of Orthopaedics, University College Hospital, London.

B Cohen, D G Shaw, M Bhamra, A M Jackson

Mothercare Department of Genetics, Institute of Child Health, 30 Guilford Street, London WC1N 1 EH.

I K Temple, M E Pembrey

Department of Paediatrics, Colchester General Hospital, Colchester, Essex.

J C Symons

Department of Radiology, Hospitals for Sick Children, London.

C M Hall

Correspondence to Professor Pembrey.

Received for publication 21 January 1991

Accepted for publication 19 February 1991.
These boys share many features in common with two female sibs seen recently in the genetic clinic (fig 1). Both girls had a syndrome distinguished from other genetic causes of short stature by the presence of marked microtia. In addition there was a characteristic facial appearance with a small mouth and small pointed chin, as seen in the patients of Hurst et al. ${ }^{1}$ The radiographic findings were unusual and remarkably similar to those described including the abnormal modelling of the glenoid fossae in one sib. The syndrome is expanded by this case report and the possibility of recessive inheritance is raised by the presence of two affected sisters. We suggest this syndrome could be called the Ear, Patella, Short stature syndrome (EPS).

\section{Case reports}

CASE 1

The proband was born to unrelated Caucasian parents aged 26 years of age. The pregnancy was

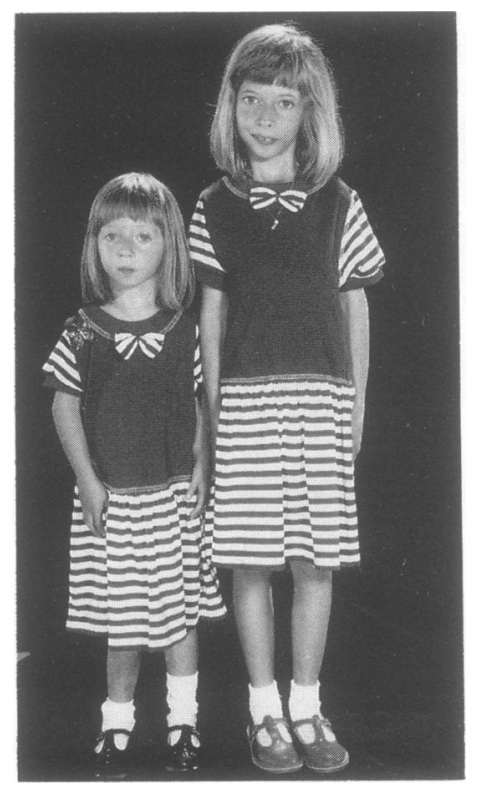

Figure 1 The sibs aged 7 years and 4 years. Note the small stature, slight build, and similar facial appearance. 
uncomplicated and the delivery normal. At birth, weight was $2400 \mathrm{~g}$ (3rd centile), length $48 \mathrm{~cm}$ (10th centile), and head circumference $34.7 \mathrm{~cm}$ (50th centile). She was noted to have bilaterally small, simple ears. There were early feeding problems with slow weight gain. Motor milestones were slightly delayed. She sat at 8 months, crawled at 1 year, and walked at 17 months. Speech was initially slower than her contemporaries but at the age of 7 years she attends a normal school and is doing well. She has a mild conductive deafness thought to be secondary to middle ear fluid. An operation to insert grommets proved unsuccessful owing to the small size of the ear canal.

On examination aged 7 years, height was $111.5 \mathrm{~cm}$ (10th centile), sitting height was $61 \mathrm{~cm}$ ( -2 SD below mean), subischial leg length was $50.5 \mathrm{~cm}(-0.5 \mathrm{SD}$ below mean), head circumference was $48.9 \mathrm{~cm}$ (3rd centile), and weight was $13.7 \mathrm{~kg}$ ( $\ll 3 \mathrm{rd}$ centile). Her ears had remained small. Both ears measured $30 \mathrm{~mm}$ (50th centile for age $57 \mathrm{~mm}$ ). The right ear is shown in fig 2 . She had a small, triangular shaped face with a small mouth and jaw and a low anterior hairline (fig 3). The palate was high and the teeth crowded. The skin appeared thin and she had prominent veins over the nose and forehead. There was clinodactyly of both little fingers. Hair and nails were normal as was the rest of the examination except for non-palpable patellae.

Investigations included a full skeletal survey. This showed delay in bone maturation of the phalangeal epiphyses of at least 12 months with marked delay in ossification and flattening of the other larger epiphyses. The patellae could not be seen. The long bones and ribs were slender. There were flat, abnormally modelled glenoid fossae with odd, hook shaped clavicles. The femoral necks were long and the iliac wings narrow. She had a normal female karyotype.

\section{CASE 2}

The proband's sister was born after a normal pregnancy at term. Birth weight was $2200 \mathrm{~g}$ ( $<3$ rd centile), length $47 \mathrm{~cm}$ (3rd to 10th centile), and head circumference was $32.5 \mathrm{~cm}(-2 \mathrm{SD}$ below mean). Bilateral microtia with small ear canals was noted at birth. Again there were early feeding difficulties and poor weight gain. She sat at 7 months, crawled at 11 months, and walked at 13 months. She was slightly slow with speech although hearing was normal. She was, however, developing appropriately for her age at 4 years and attending a normal nursery school. On examination aged 4 years, height was $89 \mathrm{~cm}$ ( $<3 \mathrm{rd}$ centile), sitting height was $51.5 \mathrm{~cm}(-3 \mathrm{SD}$ below mean), subischial leg length was $37 \mathrm{~cm}(-2 \mathrm{SD}$ below
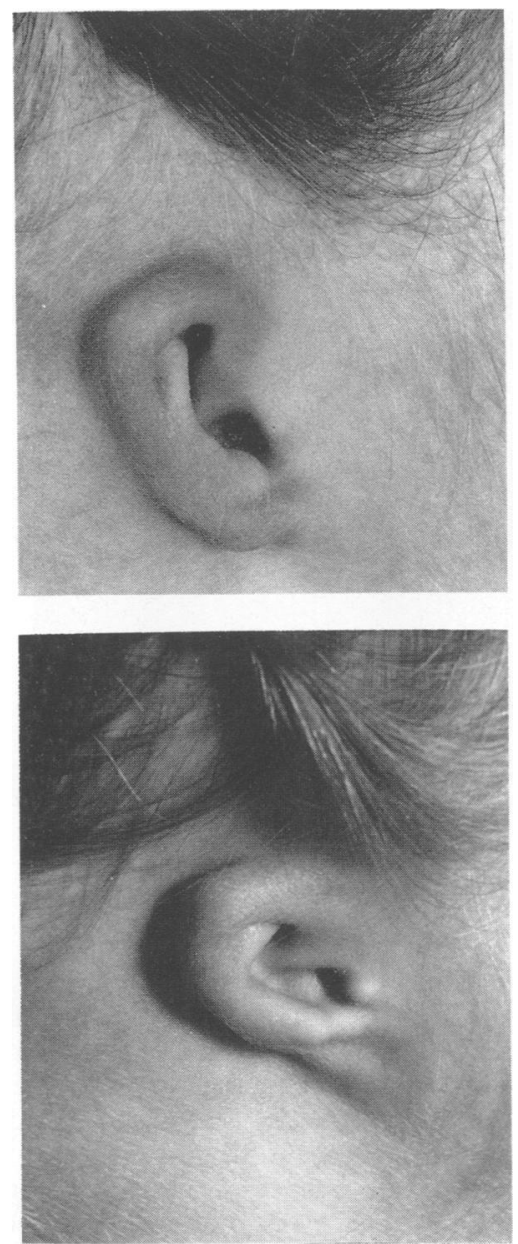

Figure 2 (Top) Right ear of case 1 aged 7 years measuring $30 \mathrm{~mm}$ and (bottom) right ear of case 2 aged 4 years measuring $24 \mathrm{~mm}$. Note they are small and simple.

mean), head circumference was $47 \cdot 3 \mathrm{~cm}$ ( $<3$ rd centile), and weight was $8.6 \mathrm{~kg}$ ( $\ll 3 \mathrm{rd}$ centile despite a voracious appetite). Ear length on the right was $24 \mathrm{~mm}$ (fig 2) and on the left was $18 \mathrm{~mm}$. The ears were simple and folded. The external auditory meatus was small but patent, and hearing was normal. She had similar facial features to her sister as shown in fig 1 . Her mouth was small. The skin was again noted to be thin particularly over the nose and the veins were prominent. She had clinodactyly of the little fingers but the hands and nails were otherwise normal. In extension she could painlessly, habitually, dislocate both elbows which spontaneously reduced in flexion. No patellae were palpable but other joints were normal with no hyperextensibility. The feet were long and thin. 


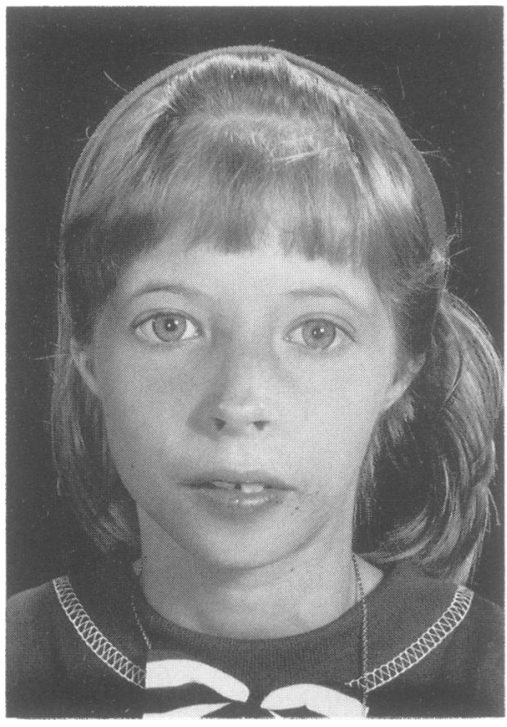

Figure 3 Case 1 aged 7 years to show her facial appearance. She has a small, triangular face and pointed nose.

A skeletal survey, performed at 10 months of age, showed marked delay in epiphyseal ossification. The upper tibial epiphyses which are normally seen at 34 weeks' gestation remained unossified. The patellae could not be seen. There were slender long bones and ribs as seen in her sister. Aged 4 years elbow dislocation was confirmed on fluoroscopy and unusually there was dislocation at both the radio-humeral and ulnar-humeral joints (fig 4). At this age there was also a genu valgum deformity with retarded maturation (corresponding to only 15 months of age) and the epiphyses were flattened (fig 5).

\section{Discussion}

Both sibs in this report have markedly small ears noted at birth, a similar facial appearance with a small mouth and jaw, and poor weight gain. Height is below the 3rd centile in case 2 and on the 10th centile in case 1 but in both sibs height velocity is progressing normally. The skeletal survey shows marked delay in bone age in both girls, flattened epiphyses, and slender long bones and ribs. The patellae are absent. The elbow dislocations in case 2 are unusual in that there is dislocation at the ulnarhumeral joints as well as the radio-humeral joints. Case 1 also has flattening of the glenoid fossae and unusual, hook shaped clavicles. This combination of features in female sibs is similar to that reported

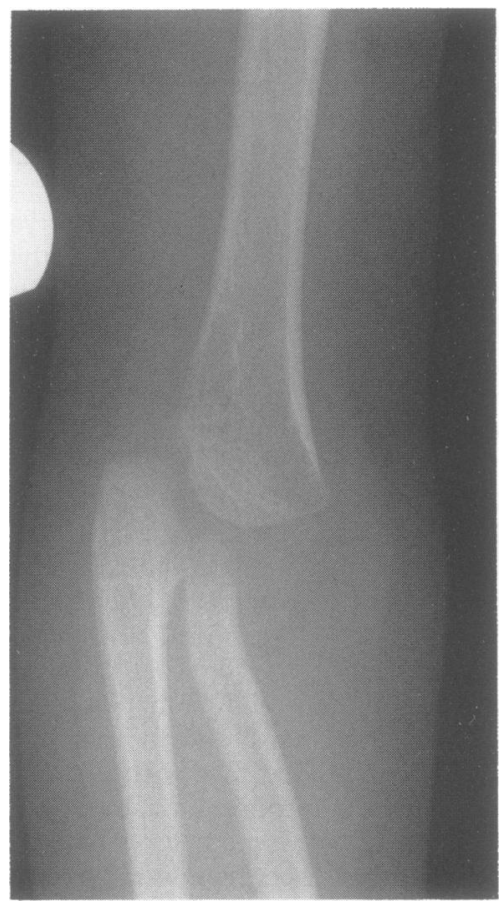

Figure 4 Radiograph of the left elbow of case 2 in extension showing dislocation of ulnar-humeral and radio-humeral joints.

by Hurst $e$ al $^{1}$ (table). Most striking is the association in all four patients of small ears, absent patellae, and short stature with similar radiographic findings. The sibs in this report differ in that their skull radiograph is normal and there is no developmental delay.

Other syndromes described with microtia and short stature were considered but thought to differ from the girls in this report. The coxoauricular syndrome, ${ }^{2}$ consisting of dislocation of the hips, spondylosis, and variable microtia, is excluded in that the pelvis is severely deformed in these children unlike the sibs in this report.

There are features in common with other short stature syndromes. The $3 \mathrm{M}$ syndrome is characterised by short stature with minor associated skeletal findings including dislocation of the elbow and radiographic evidence of slender bones and tall vertebrae. Facial features differ in that patients have frontal bossing, a fleshy nasal tip, and upturned nares. Ears are sometimes prominent in the $3 \mathrm{M}$ syndrome ${ }^{3}$ but are not markedly small. RussellSilver syndrome is also excluded in that microtia of the degree reported in the sibs has not been described. Type II osteodysplastic primordial dwarfism causes disproportionate and more severe short 


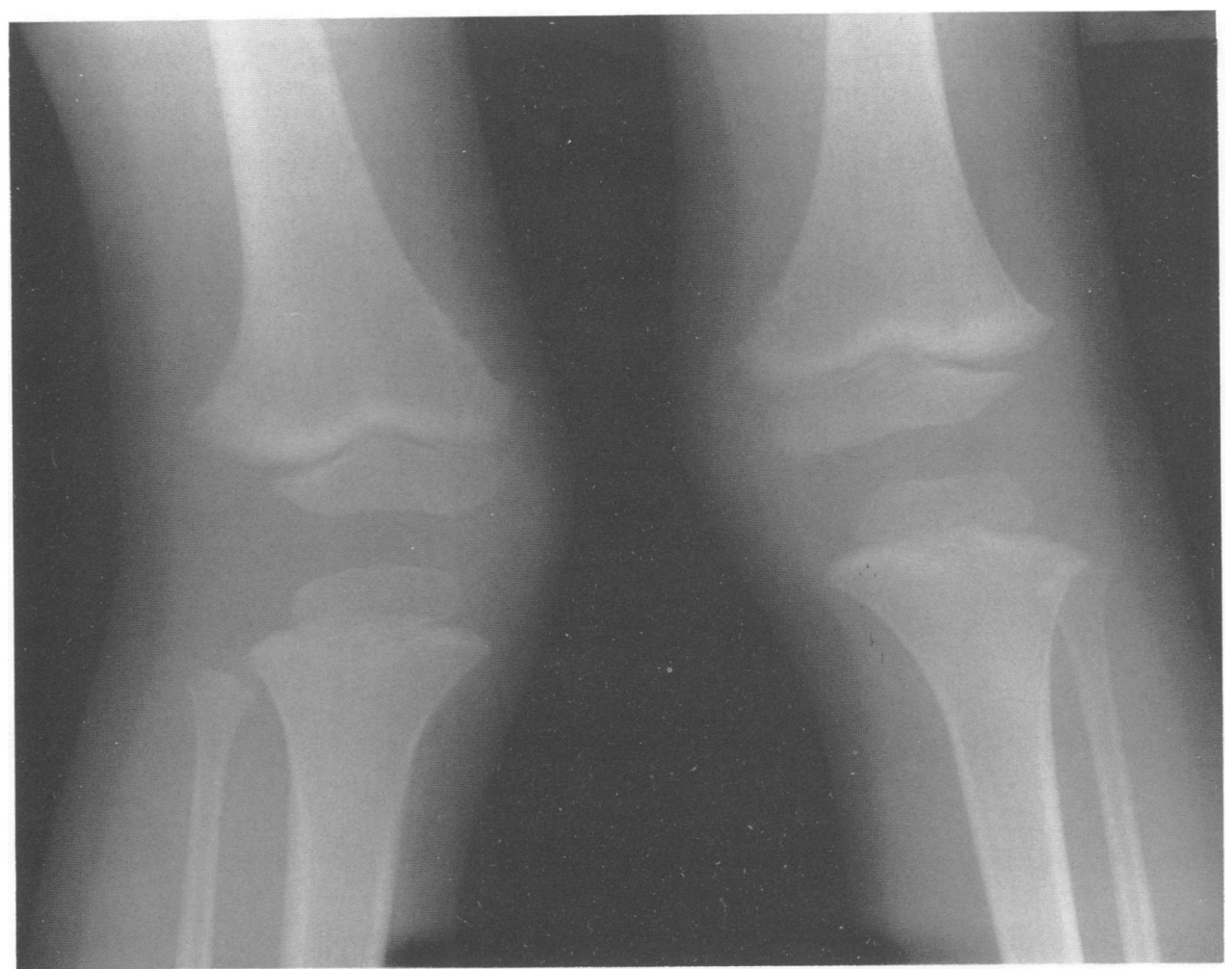

Figure 5 Genu valgum in case 2 at the age of 4 years showing a bone maturation of 15 months, flattened epiphyses, and slender long bones.

stature associated with microcephaly and mental retardation, not seen in the two sibs.
We report these sibs to draw to the attention of other clinicians this short stature syndrome which

Features of the patients of Hurst et al ${ }^{1}$ and present patients.

\begin{tabular}{|c|c|c|c|c|}
\hline \multirow[b]{2}{*}{ Features } & \multicolumn{2}{|c|}{ Hurst et $a l^{1}$} & \multirow[b]{2}{*}{ Sib 1} & \multirow[b]{2}{*}{ Sib 2} \\
\hline & Patient A & Patient B & & \\
\hline Birth weight ( $<3$ rd centile) & $?$ & + & 3rd & + \\
\hline Proportionate short statute & + & + & $\begin{array}{l}\text { 10th } \\
\text { centile }\end{array}$ & + \\
\hline Microcephaly & + & + & - & + \\
\hline Small ears & + & + & + & + \\
\hline Small mouth/small jaw & + & + & + & + \\
\hline Short neck & + & + & - & - \\
\hline Absent patellae & + & $?$ & + & + \\
\hline Delayed skeletal maturation & + & + & + & + \\
\hline Slender bones & + & + & + & + \\
\hline Flattened epiphyses & + & $?$ & + & + \\
\hline Glenoid fossa & Shallow & Absent & Shallow & Normal \\
\hline 'Hooked' clavicles & + & + & + & - \\
\hline Elbow dislocation & - & - & - & + \\
\hline Gaps in ribs & - & + & - & - \\
\hline Clinodactyly & $?$ & $?$ & + & + \\
\hline Seizures & + & $?$ & - & - \\
\hline Mental retardation & + & $?$ & - & - \\
\hline
\end{tabular}


may be easily identified at birth by the small, simple ears. Autosomal recessive inheritance or germinal mosaicism are possible modes of inheritance.

We would like to thank the family for their help with this paper and Dr Robin Winter for his helpful and timely discussions.
1 Hurst JA, Winter RM, Baraitser M. Distinctive syndrome of short stature, craniosynostosis, skeletal anomalies and malformed ears. Am $\mathcal{f}$ Med Genet 1988;29:107-15.

2 Duca D, Pana I, Ciovirache M. A previously unreported, dominantly inherited syndrome of shortness of stature, ear malformations, and hip disolocation: the coxoauricular syndrome - autosomal or X-linked male-lethal. Am f Med Genet 1981;8:173-80.

3 Miller JD, McKusick VA, Malvaux P, Temtamy S, Salinas C. The 3M syndrome: heritable low birth-weight dwarfism. Birth Defects 1975;XI(5):39-47. 